Check for updates

Cite this: Energy Adv., 2022, 1, 159

Received 23rd November 2021 Accepted 21st January 2022

DOI: $10.1039 /$ d1ya00057h

rsc.li/energy-advances

\section{Enzymatic ethanolysis of high free fatty acid jatropha oil using Eversa Transform}

\author{
Abderrahim Bouaid, ${ }^{a}$ Hassan Acherki, ${ }^{a}$ Marcos Herguedas Bonilla ${ }^{a}$ and \\ Jorge Mario Marchetti $(D * b$
}

\begin{abstract}
The reduction of the cost of enzymatic biodiesel is crucial to make it competitive with more well-known and settle technologies; therefore, there is a need for a single-step process for the conversion of high free fatty acid oils into fatty acid ethyl esters (FAEEs) using a low-cost lipase. Jatropha oil, with high free fatty acid (FFA) content (9.4\%), was transformed into biodiesel using a lipase (Eversa Transform 2.0 Novozymes) as the catalyst and ethanol as the alcohol. The optimization of reaction yields was carried out using a factorial design (FD) and response surface methodology (RSM). The obtained models were used to determine the optimum operating conditions for an upscaling scenario, and provided a thorough understanding of the reaction mechanism. The factorial design was developed with the varying temperature (between 30 and $40{ }^{\circ} \mathrm{C}$ ) and amount of catalysts (between 5 and $9 \mathrm{wt} \%$ ), while the alcohol/oil molar ratio was kept constant at $6: 1$. It was found that the highest achievable yields, within the range of operating conditions tested, were reached when the catalyst concentration was $4.2 \%$, the alcohol/oil molar ratio was $6: 1$ and the operation temperature was $36{ }^{\circ} \mathrm{C}$ with model $R^{2}=91.77$ for the linear model. Within these operating conditions, the yield of FAEE was above $98 \%$. The FAEE produced can be used as a promising substitute for petroleum-based diesel fuels, since it fulfills the European Biodiesel Standard EN 14214 in all aspects tested except for the oxidation time.
\end{abstract}

\section{Introduction}

Meeting the demand for sustainable energy with minimum environmental impacts is a major area of concern in the energy sector. Nowadays, biodiesel (fatty acid alkyl esters) is considered as an important alternative biofuel to satisfy these energy needs, due to its environmental benefits and simple production from renewable resources.

Biodiesel is synthesized via the transesterification reaction of triglycerides such as non-edible or edible vegetable oils with alcohol using an appropriate catalyst that produces the fatty acid alkyl ester and glycerol. Vegetable oils have higher viscosity around 10-15 times and lower fluctuations than diesel fuel. Therefore, the direct use of vegetable oils is limited in diesel engines due to incomplete combustion and fuel deposition in the injector. ${ }^{1}$

The transesterification reaction has been widely used to reduce the viscosity of vegetable oils to improve their characteristics for use as a biodiesel or green fuel in the diesel engine. ${ }^{2}$ In the transesterification reaction, base catalysts such

\footnotetext{
${ }^{a}$ Chemical Engineering Department, Faculty of Chemistry,

Universidad Complutense de Madrid, 28040, Madrid, Spain

${ }^{b}$ Faculty of Science and Technology, Norwegian University of Life Science,

Drøbakveien 31, 1432 Ås, Norway. E-mail:jorge.mario.marchetti@nmbu.no
}

as potassium hydroxide, sodium hydroxide, sodium or potassium methoxide and calcium methoxide are commonly used. ${ }^{3}$

Traditionally, potassium hydroxide is mainly used in biodiesel production due to its higher performance in the industry, high availability, high compatibility, and economic efficiency. ${ }^{4}$

One of the most widely used methods for the purification of biodiesel produced using homogenous catalysts is to wash out the impurities with water. Water has a very low affinity for biodiesel, and absorbs excess alcohol, catalysts and soap suspended in the fuel. Water washing has its drawbacks. It is a time-consuming step that requires many hours for the biodiesel and water to separate. In addition, since virtually all biodiesel production processes use homogeneous alkaline catalysts, the presence of soap can create emulsification problems, the separation process will be more difficult, and consequently, the final costs increase. ${ }^{5}$

The enzymatic pathway to produce biodiesel using low-cost, high free fatty acid oils has attracted much attention recently due to its environmental benefits such as sustainability, renewability, green nature, minimum water and energy consumption and capability of treating waste oil.

This is in line with the latest steps that not only scientific community is taking but also industries, which are moving towards the use and development of environmentally benign or "green" approaches. The principles of green chemistry focus on 
reducing, recycling, or eliminating the use of toxic chemicals in chemistry by finding creative ways to minimize the human and environmental impact without stifling scientific progress. ${ }^{6}$

The use of food-based biofuels has been a subject of debate for a long time, due to their negative environmental and social impacts, as well as the climatic impacts linked to arable land use. The amount of $\mathrm{CO}_{2}$ emissions increases considerably when the existing agricultural land is employed to produce crops that will then be used for biofuels instead of food and feed. Therefore, food and feed production must expand elsewhere to meet the world's growing demand. ${ }^{7}$

The EU push for crop-based biodiesel led to the creation of an additional market for agricultural commodities. Between 2005 and 2015, vegetable oil consumption decreased in the food sector (from 15.1 to 13.7 million tons), whereas it almost quadrupled in the bioenergy sector (going from 2.9 to 10.5 million tons). ${ }^{8}$

According to the data from Oil World, almost $2 / 3$ of the rapeseed consumed within the EU is for biodiesel, the absolute volume staying stable since 2009 . Cheaper vegetable oil commodity such as palm oil has grown in this period. Overall, $44 \%$ of all vegetable oils (from palm, soy, rapeseed and sunflower) in Europe are consumed as biodiesel. In 2015, the EU adopted a $7 \%$ limit on the number of food-based biofuels to be counted in the $10 \%$ transport renewables target, as a measure to address Indirect Land Use Change (ILUC). ${ }^{9}$

At present, most of the commercial biodiesel plants in North America and Europe are using edible oils such as canola, soybean and rapeseed oils, which not only takes food from tables but also accounts for $70-95 \%$ of the total biodiesel production cost. ${ }^{10}$

Due to the global increase in the energy demand and therefore of liquid fuels, there is a net increase in the productions of oils for biofuel production, and this has raised food security concerns and ethical "food $v s$. fuel" issues. ${ }^{11}$

In addition, biodiesel cost is almost $1 / 3$ more expensive than their petroleum counterpart and this is mainly due to the expensive raw materials used known as first-generation biodiesel feedstock. ${ }^{12}$ Therefore, it is imperative to source and identify low-cost and underutilized feedstocks for biodiesel production.

Hence, production of biodiesel at a lower cost focusing on non-edible feedstocks such as non-edible vegetable oils, ${ }^{13}$ used cooking oils, ${ }^{14}$ and waste animal fats, ${ }^{15}$ known as secondgeneration biodiesel feedstock, has become a recent trend. ${ }^{12}$ High concentrations of water and free fatty acid (FFA) in second-generation feedstocks have been a challenge, especially when processed through alkaline-catalysed esterification/ transesterification. ${ }^{16,17}$

According to Zhang et al., ${ }^{18}$ only refined oils with an acid value less than $1 \mathrm{mg} \mathrm{KOH} \mathrm{g}^{-1}$ could be used in an alkalicatalysed process. A pre-treatment step was required for oils having an acid value higher than $2 \mathrm{mg} \mathrm{KOH} \mathrm{g}{ }^{-1}$. Nevertheless, some authors had also successfully carried out the alkali-catalysed transesterification of used cooking oils having an acid value up to $4.91 \mathrm{mg} \mathrm{KOH} \mathrm{g}{ }^{-1} \cdot{ }^{19}$
Ideally, biodiesel needs to be $100 \%$ fatty acid alkyl esters, but practically, low conversion, side reactions and difficulty in product separation result in the presence of impurities in biodiesel. A higher conversion of feedstock oils to esters gives better engine performance. ${ }^{20}$ Many impurities in biodiesel such as glycerol, monoglycerides and diglycerides appear unfavourable for optimum engine performance. ${ }^{21}$ The determination of biodiesel quality is an issue of great importance to successfully commercialize biodiesel. ${ }^{22}$

To ensure customer's acceptance, standardization and quality assurance are key factors for the market introduction of biodiesel as a fuel for transport and heating. One of the major problems associated with the use of biodiesel as supply for diesel engines is poor low-temperature flow properties. Pure biodiesel can solidify in fuel lines or clog filters when utilized under cold ambient conditions. ${ }^{23}$ Another important criterion for the quality of a biofuel is its storage stability. Resistance to oxidative degradation during storage is an increasingly important issue for the successful development and viability of alternative fuels. ${ }^{24}$

During storage, the viscosity of the esters increases owing to the formation of oxidized polymeric compounds that can lead to the formation of gums and sediments that clog filters. The formation of higher molecular weight species, which possess higher viscosity, is a reason that the viscosity specification in biodiesel standards can be used to assess the fuel quality status of the stored biodiesel. ${ }^{16}$

Jatropha curcas is a plant belonging to Euphorbiaceae family that produces a significant amount of oil from its seeds. This is a non-edible oil-bearing plant widespread in arid, semi-arid and tropical regions of the world. Even more, this tree is a droughtresistant perennial tree and can live over 50 years. ${ }^{25}$ It can be grown in areas where no food-based crops could have been planted, reducing its competitiveness against edible oils and arable land.

Hence, the contribution of non-edible oils such as jatropha oil will be significant as a non-edible plant oil source for biodiesel production. The biodiesel from Jatropha curcas oil is a promising 2nd-generation biofuel because it has a low price, it is easily available, and it can be produced in a sustainable and renewable way.

In the biodiesel production process, the alcohol employed is generally methanol because it is the least expensive alcohol. However, this alcohol presents several drawbacks such as high toxicity, being synthesized from non-renewable sources, can be absorbed through the skin and is $100 \%$ miscible with water, so any kind of spill presents a serious problem. Ecological aspects are gaining a lot of recognition in our society. ${ }^{26}$

Microbial production of ethanol is one of the first large-scale industrial fermentation processes of global importance. Bioethanol is derived from agricultural products and can be produced in a renewable and sustainable way. ${ }^{27}$ Bioethanol is safer to handle compared to methanol because toxic effects to humans from exposure to fumes are reduced. The production of ethyl esters, rather than methyl esters, has shown to be more appealing in today's society as this renewable fuel can be considered as an agricultural fuel. ${ }^{26}$ 
Enzymatic transesterification reactions using lipases show many advantages over traditional catalysts: they show high selectivity, allow to work under mild operating conditions, have no significant side reactions, and yield products of high purity. ${ }^{28}$

Enzymes can convert a wide variety of substrates and catalyse many different types of reactions; therefore, they have numerous applications in food, pharmaceutical, detergent, animal feed, and biofuel industries. ${ }^{29-32}$ However, most native enzymes are not suitable to be directly applied in the industry; for example, they need to be stabilized to work properly under non-natural conditions. ${ }^{33,34}$

Currently, many large-scale processes within the segments of detergent, starch, textile, fuel alcohol, pulp and paper, and biodiesel production use soluble enzymes, predominantly hydrolases (e.g., amylases, proteases, cellulases and lipases). ${ }^{35}$

However, the use of lipases for biodiesel production may present some problems; in fact, lipase stability and reusability under the conditions used in biodiesel production are limited, the process is slower than using alkaline catalysis, and in many instances, the yields are also lower.

A solution to overcome these limitations can be to consider the use of nanostructures to support enzyme immobilization, thus obtaining new heterogeneous biocatalysts. ${ }^{36}$

For economic reasons and for reusability and recycling, the lipases urged to be immobilized on suitable supports, thus the concept of heterogeneous bio-catalysis comes into existence. Regarding lipase immobilization, different techniques were approached. $^{36}$

One lipase produced and applied on a large scale in several industrial processes is the lipase from Thermomyces lanuginosus (formerly Humicola lanuginosa) (TLL). ${ }^{37}$ It has been reported that TLL immobilized on a hydrophobic matrix produced by Purolite offered very good results in the synthesis of biodiesel using different oils. ${ }^{38,39}$

To supply the billion-dollar market of enzymes, large companies offer formulations of soluble enzymes for large-scale applications of industrial processes. Regarding the energy sector for biofuel production (e.g., biodiesel and 2G ethanol), new enzyme formulations are frequently launched to the market with enhanced stability and functionality.

One example is the lipase product Eversa Transform launched by Novozymes as a commercially available liquid enzyme preparation from Thermomyces lanuginosus with enhanced ability to convert waste oils into biodiesel. ${ }^{40}$ Recent studies on this lipase have indicated improved enzyme reusability of up to 12 times, and increased biodiesel yield from soybean oil (>97\%) and rapeseed oil (92-97\%), ${ }^{41}$ showing very promising results within the field of biofuels.

Eversa Transform 2.0 was launched on the market at a lower cost compared to the traditionally used enzymes (20.0 USD $\left.\mathrm{kg}^{-1}\right),{ }^{42}$ making the production of biodiesel by enzymatic catalysis using low-cost oily feedstocks promising. ${ }^{43,44}$

Biodiesel production using liquid enzyme Eversa Transform as the catalyst, without enzyme reuse, resulted in a production cost of $0.78 \mathrm{USS}^{-1}$, corresponding to a profit of 51.6 million US\$ year $^{-1}$, for an annual biodiesel production of 250000 tons. $^{45}$

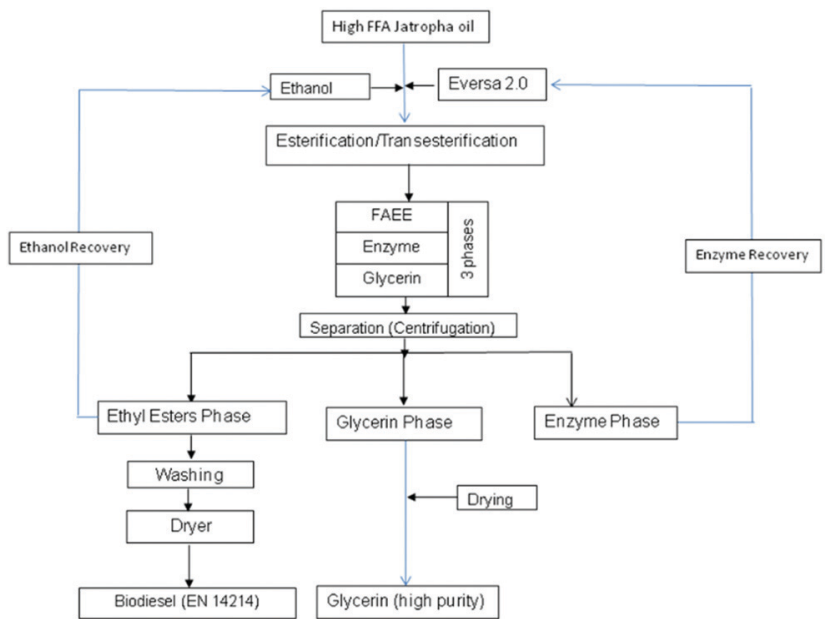

Fig. 1 Schematic of biodiesel production from high FFA Jatropha oil via a one-step enzyme-catalysed process

In this context, high free fatty acid non-edible Jatropha oil was used as a cheap feedstock, and a direct single-step enzymatic-catalysed process to produce a high-quality biodiesel was carried out using Eversa as the catalyst and bioethanol as the alcohol.

This one-step process is presented in Fig. 1.

The enzymatic process of ethanolysis of jatropha oil has been studied. Optimization using factorial design and response surface methodology was carried out for 2 main variables (temperature and catalyst amount). A factorial design of experiments was employed since it allows us to understand the interactions of different variables simultaneously in comparison with the regularly used one-variable variation approach. $^{46}$

Factorial design of experiments gives more information per experiment than unplanned approaches; it allows us to see the interactions among experimental variables within the range studied, and it facilitates the determination of the operating conditions necessary for the scale-up of the process, leading to better knowledge of the process and, therefore, reducing research time and costs. In this sense, the methodology has been used extensively to develop and optimize different ester synthesis processes. ${ }^{47,48}$

\section{Material and methods}

\section{Equipment}

A stirred batch reactor of $250 \mathrm{~cm}^{3}$ volume was used. The equipment was provided with temperature and speed control and immersed into a thermostatically controlled water bath, the temperature of which was controlled using a PID controller with $1{ }^{\circ} \mathrm{C}$ precision. The speed of the mechanical stirrer was monitored using a motor (IKA-labortechnik). The impeller speed was set between 300 and $600 \mathrm{rpm}$ and a value of $350 \mathrm{rpm}$ was found appropriate to overcome the external mass transfer limitation. ${ }^{49}$ 


\section{Materials}

Jatropha oil was supplied by Gracomsa Alimentaria (Valencia, Spain). The FFA content of the oil was determined according to the AOCS official method. The fatty acid composition and its physicochemical properties are presented in Table 1. Ethanol of 99.8\% purity was supplied by Panreac (Spain). The catalyst used, Novozymes Eversa Transform 2.0, was supplied by Novozymes (Denmark).

\section{Procedure}

The jatropha oil was added to the reactor and the steering and temperature were set. When the desired temperature was achieved, the enzyme and the alcohol, that were mixed and warmed up separately from the oil, were added, and then the impeller speed was fixed to the operating value and the time started. The samples were withdrawn at specific times and intervals and analysed by gas chromatography. During the experiments, the impeller speed (350 rpm) and pressure (atmospheric) were kept constant.

The range for the factors chosen was based on the preliminary work done, taking into consideration the experimental installations and its limitations. Based on this, the temperature range was set between 28 and $42{ }^{\circ} \mathrm{C}$, and a temperature below $28{ }^{\circ} \mathrm{C}$ does not lead to an effective activity of the enzyme, and the yields were not suitable for industrial applications; a temperature higher than $42{ }^{\circ} \mathrm{C}$ will make the enzyme lose its activity due to the temperature, as reported elsewhere. ${ }^{50}$ The levels of catalyst concentration were chosen based on the preliminary experiment as well as based on literature, and it is usually between 3 and $10 \mathrm{wt} \% ;^{51}$ the amount of catalyst was progressively increased, and the ester yield was monitored versus time. The levels chosen were 4.2 and $9.8 \mathrm{wt} \%$ of the whole mass reaction.

High yields were obtained when a molar ratio of $6: 1$ was used. It was also found that the yield decreased considerably when the largest excess of ethanol was present in the reaction medium due to the possible inhibitory effects on the enzyme. Thus, alcohol in excess was used in the present work with the limitation not to exceed a 6:1 molar ratio.

\section{Reaction time}

Reaction time plays a crucial role in the process, and it is hardly linked to economic aspects and energy consumption.

Table 1 Characteristics of jatropha oil and fatty acid composition

\begin{tabular}{lc}
\hline Characteristics & Jatropha oil \\
\hline Acid number $\left(\mathrm{mg} \mathrm{KOH} \mathrm{g}^{-1}\right)$ & 18.78 \\
Iodine number $\left(\mathrm{I}_{2} / 100 \mathrm{~g}^{2}\right)$ & 115 \\
Viscosity $\left(40{ }^{\circ} \mathrm{C}\right)\left(\mathrm{mm}^{2} \mathrm{~s}^{-1}\right)$ & 38.76 \\
Density at $30{ }^{\circ} \mathrm{C}\left(\mathrm{g} \mathrm{mL}^{-1}\right)$ & 0.92 \\
& \\
Fatty acid compositions $(\%)$ & 13.72 \\
Palmitic $(\mathrm{C} 16: 0)$ & 18.52 \\
Stearic $(\mathrm{C} 18: 0)$ & 45.61 \\
Oleic $(\mathrm{C} 18: 1)$ & 21.18 \\
Linoleic $(\mathrm{C} 18: 2)$ & 0.2 \\
Linolenic $(\mathrm{C} 18: 3)$ & 0.77 \\
Other acids &
\end{tabular}

Preliminary studies were done to set the optimal reaction time, and it was determined that the reaction time should be set to $4 \mathrm{~h}$ with an optimal yield of $95.08 \%$. A further increase in reaction time did not affect the ethyl ester yield. This may be due to the reverse reaction leading to the loss of fatty acid ethyl ester production. ${ }^{52}$

\section{Analytical methods}

The fatty acid ethyl ester profile was measured by capillary column gas chromatography, using a Hewlett-Packard 5890 series II equipped with a flame ionization detector (FID). The injection system was split-splitless. The carrier gas was helium at a flow rate of $1 \mathrm{~mL} \mathrm{~min}^{-1}$, and the separation program consisted of an initial oven temperature of $120{ }^{\circ} \mathrm{C}$ ramped at $5{ }^{\circ} \mathrm{C} \mathrm{min}{ }^{-1}$ to $160{ }^{\circ} \mathrm{C}$, then at $20{ }^{\circ} \mathrm{C} \min ^{-1}$ to $320{ }^{\circ} \mathrm{C}$ with a $20 \mathrm{~min}$ hold to complete the program. The internal standard technique was used to quantify the amount of the chemical species. The other analysis operating conditions have been described in detail in a previous work. ${ }^{53}$ Biodiesel samples were monitored and analysed according to the following American Oil Chemistry Society (AOCS) procedures: acid value AV (AOCS Ca 5a-40), iodine value IV (AOCS Cd 1-25), moisture content (Karl Fischer method) and viscosity $\nu$ (ISO 3104). The oxidation stability of ethyl esters was measured according to the Rancimat method ASTM D97 using a Metrohm 743 Rancimat (Herisau, Switzerland). The cloud point (CP), the pour point (PP) and cold filter plugging point (CFPP) of ethyl esters were measured using an Automatic analyzer (Cloud and Pour point measurements CPP 97-2), according to the ASTM D2500 method.

\section{Ethyl ester purification}

After the elapsed reaction time, the sample was decanted and separated to remove glycerol and enzyme phases. After the two phases of glycerol and enzyme were separated from the rest, the remaining ethanol in the ethyl ester phase was removed by evaporation under vacuum to be reused. The ethyl ester phase was purified by washing gently with water to remove the rest of glycerol and enzyme. The final water content of the jatropha ethyl esters was less than $0.02 \%$. The enzyme was separated from the glycerol phase by decantation with the aim of later recovery and use.

\section{Statistical analysis}

The synthesis of ethyl esters was studied using a factorial design of experiments where a full two-level factorial design $2^{2}$ (two factors each at two levels) amplified to Response Surface Methodology (RSM) was employed. Application of this method requires the adequate selection of response, factors, and levels.

The response selected, $Y$, was the yield of ethyl ester. The selection of factors was made considering chemical and economic benchmarks of the process. The factors chosen were reaction temperature, $X_{\mathrm{T}}$, and catalyst concentration, $X_{\mathrm{C}}$. The remaining operational variables were kept constant as mentioned previously. 
Table 2 A $2^{2}$ Factorial experiment matrix: experimental results

\begin{tabular}{llllll}
\hline Runs & $X_{\mathrm{C}}$ & $X_{\mathrm{T}}$ & $C(\%)$ & $T\left({ }^{\circ} \mathrm{C}\right)$ & $Y(\%)$ \\
\hline 1 & -1 & -1 & 5 & 30 & 87.90 \\
2 & +1 & -1 & 9 & 30 & 92.57 \\
3 & -1 & +1 & 5 & 40 & 96.19 \\
4 & +1 & +1 & 9 & 40 & 96.00 \\
5 & 0 & 0 & 7 & 35 & 95.92 \\
6 & 0 & 0 & 7 & 35 & 94.22 \\
7 & 0 & 0 & 7 & 35 & 92.86 \\
8 & 0 & 0 & 7 & 35 & 93.68 \\
9 & $-\alpha$ & 0 & 4.2 & 35 & 97.12 \\
10 & $+\alpha$ & 0 & 9.8 & 35 & 95.25 \\
11 & 0 & $-\alpha$ & 7 & 28 & 93.63 \\
12 & 0 & $+\alpha$ & 7 & 42 & 94.88
\end{tabular}

The experimental matrix for the factorial design is shown in Table 2 . The first two columns of data show the " \pm 1 " coded factor levels in the dimensionless co-ordinate and the next two show the factor levels on a natural scale. All experimental runs were randomly performed. For experimental error estimation, four experiments were carried out at the central point level, coded as ' 0 '. The use of analysis and factorial design of experiments allowed the expression of the amount of ethyl esters produced as a polynomial model. If the levels of the factors are equally spaced, then orthogonal polynomials may be used. Hence, we can display the response, which is the theoretical yield of ester, as a function of the significant factors and their interactions.

\section{Results and discussion}

\section{Linear stage}

The experimental design applied in this study was a $2^{2}$ factorial design, to which four central points were added to evaluate the experimental error. The experimental results obtained are shown in Table 2.

The data were analysed, and its statistical significance was calculated; this can be seen in Table 3. Temperature $\left(X_{\mathrm{T}}\right)$, catalyst concentration $\left(X_{\mathrm{C}}\right)$ effects and their interactions were fitted by multiple regression analysis to a linear model. The response function for the main significant effects and interactions can be expressed using eqn (1) as follows:

$$
Y_{\mathrm{EE}}=93.58+1.12 X_{\mathrm{C}}+2.93 X_{\mathrm{T}}-1.22 X_{\mathrm{TC}} \quad r=0.95
$$

As observed in the statistical analysis, the most positive significant factor is the temperature reaction. As observed in the statistical analysis (Table 3), the most positive significant factor is the temperature followed by the catalyst concentration. The interaction effect is significant and negative due to the deactivation of the enzyme at higher temperature values.

The comparison of the results from the linear model, experimental and predicted, is presented in Fig. 2.

\section{Non-linear stage}

A second-order model was required for the analysis of the yield of ethyl esters due to the significance of the curvature effect found in the linear stage, and the experiments were amplified using a response surface methodology. Star points as additional experimental points had to be incorporated into the twolevel factorial design for the two significant factors, reaction temperature and catalyst concentration. The full central composite design, adapted from Box and Wilson $(1951)^{54}$, including factorial points, centre-points and star points is shown in Table 2. The corresponding model is the complete quadratic surface between the response and the factors, as shown in eqn (2) as follows:

$$
Y=a_{0}+\sum_{k=1}^{2} a_{k} X_{k}+\sum_{k=1}^{2} a_{k k} X_{k}^{2}+\sum_{k \neq j}^{2} a_{k j} X_{k} X_{j} .
$$

where: $a_{0}$ is a constant; $a_{k}, a_{k k}$, and $a_{k j}$ are the regression coefficients; $X_{k}$ and $X_{j}$ are independent variables; $Y$ is the yield of esters (\%).

Four additional runs, called star points and coded $\pm \alpha$, were added to the $2^{2}$ factorials plus centre-points to form a central composite design, where $\alpha$ is the distance from the origin to the star point, as given by $\alpha=2^{n / 4}$; in the design, $\alpha=1.41$. The coefficients of eqn (2) were determined by multiple regression analysis. This analysis includes all the independent variables

Table 3 A $2^{2}$ Factorial design for linear model: statistical analyses for ethyl esters

Response: Yield of ester after $4 \mathrm{~h}$ of reaction

Number of runs: 4

Freedom degrees: 3

Results of statistical analysis

$Y=93.58$

Interactions

$X_{\mathrm{T}}=2.93$

$X_{\mathrm{C}}=1.12$.

$X_{\mathrm{TC}}=-1.22$

Significance test

Confidence level: $95 \%$

$Y_{\mathrm{C}}=94.17$

Confidence range: \pm 1.78

$S=1.29$

$t=2.77$

Main effects and interactions: $X_{\mathrm{C}}(+), X_{\mathrm{T}}(+), X_{\mathrm{TC}}(-)$

Curvature: $C=Y-Y_{\mathrm{C}}=0.59$

Curvature effect: \pm 2.52

Response equation

$Y=93.58+1.12 X_{\mathrm{C}}+2.93 X_{\mathrm{T}}-1.22 X_{\mathrm{TC}} \quad r=0.95$ 


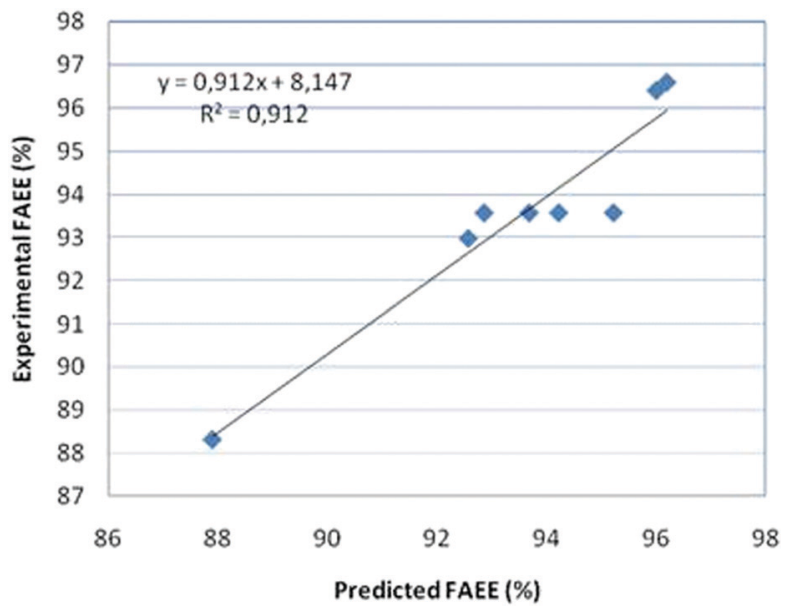

Fig. 2 Comparison of the predicted and experimental results for the linear model.

and their interactions, regardless of their significance levels. The best fitting response surfaces can be expressed by the following statistical model:

$Y_{\mathrm{EE}}=94.17+0.23 X_{\mathrm{C}}+1.46 X_{\mathrm{T}}-0.22 X_{\mathrm{TC}}+0.42 X_{\mathrm{C}}^{2}+0.24 X_{\mathrm{T}}^{2}$

$$
r=0.97
$$

where: $X_{\mathrm{C}}$ is the amount of catalysts; $X_{\mathrm{T}}$ is the temperature value.

The statistical model was obtained from coded levels. Eqn (3) is represented as dimensional surface plots (Fig. 3), revealing the predicted yields for ethyl ester within the investigated range of initial catalyst concentration and temperature.

As each of the studied variables presented a different influence on the yield, positive and negative, in the following subsection, the influence of the variable's catalyst concentration, reaction temperature and interactions on ethyl ester yields will be discussed in detail.
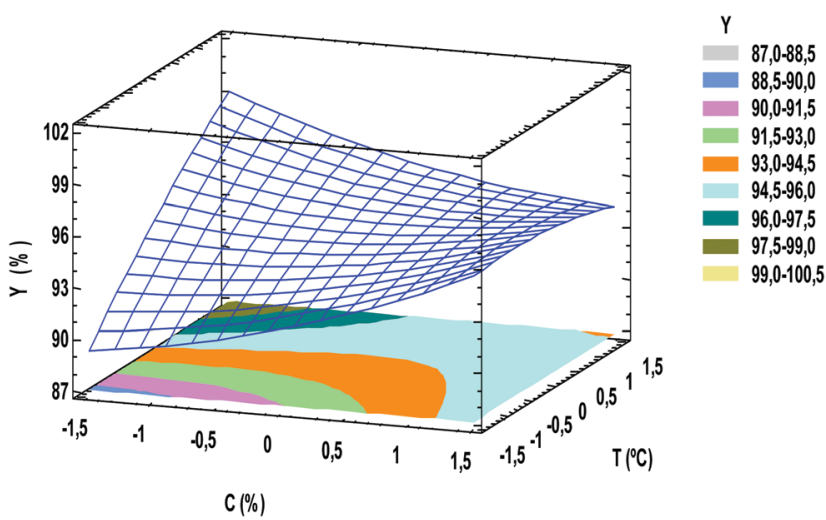

Fig. 3 Response surface and contour plot of ethyl ester yield as a function of catalyst concentration and temperature.

\section{Influence of the temperature}

Most of the enzymatic transesterification reactions depend on the temperature, which enhances the activity of lipase, reaction rate and yield of fatty acid alkyl esters.

The influence of the temperature reaction is statistically significant in the studied range $\left(28-42{ }^{\circ} \mathrm{C}\right)$. This variable has a positive influence and, therefore, increases in its value will increase the amount of biodiesel produced. This behaviour is expected in the presence of endothermic reactions, as it is the production of biodiesel.

A different scenario can be seen for the modification in the amount of catalysts, as can be seen in Fig. 4; at low catalyst concentrations, an increase in temperature increases the ethyl ester yield from 91.5 to $97 \%$. However, when the catalyst concentration was set at its high value, the increase in temperature from low to high value increases the ethyl ester yield very slightly from 94.1 to $94.4 \%$. This behaviour could be related to the amount of catalytic material being slightly deactivated due to the increase in the temperature in combination with reaching a saturation amount of enzyme in the system, leading to no modification in the conversion when larger quantities of catalyst are in the reactor.

The increase in temperature increases the solubility of the alcohol in the oil, and this improved mass transfer between the reactants ${ }^{55}$ due to the better dispersion of the catalyst particle in a liquid medium, which may explain a positive effect on the conversion. In addition, higher temperatures would also increase the reaction rate and decrease the reaction time due to the reduction in the viscosity of the oils. However, it is possible that higher temperatures than those employed in this work may accelerate the deactivation of the enzyme. Therefore, working temperatures in the range of $35-40{ }^{\circ} \mathrm{C}$ are recommended to extend the operational stability of the catalysts.

\section{Influence of the initial catalyst concentration}

The amount of enzymes used for biodiesel production is a crucial factor for successful industrial applications. ${ }^{56}$ The influence of the

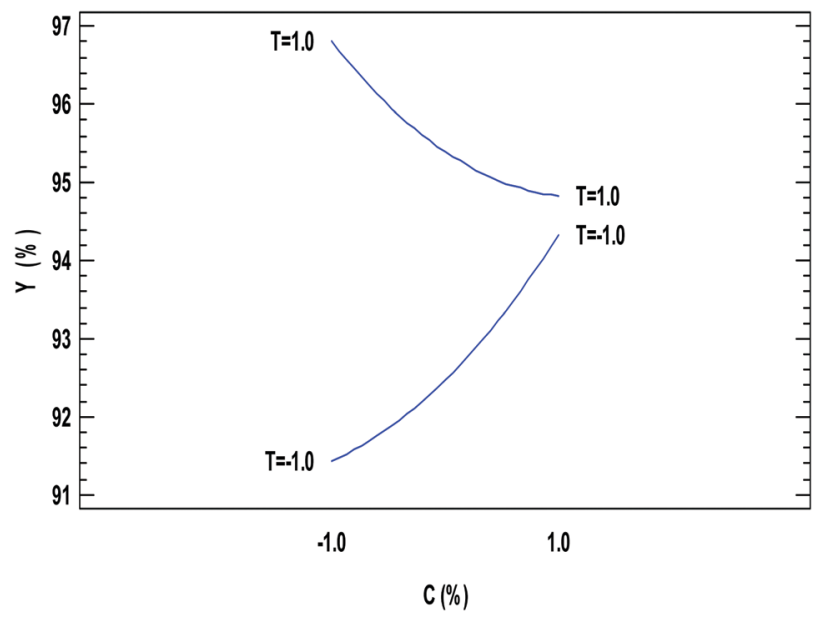

Fig. 4 Interaction factor plots of ethyl ester yields for the second-order model. 
biocatalyst amount in the reaction yield was evaluated by increasing the catalyst amount from $4.2 \%(-\alpha)$ to $9.8 \%(+\alpha)$.

The statistical analysis shows that within the experimental range, the initial catalyst concentration is a significant factor affecting the transesterification process for ethyl ester production with a positive influence on the response.

Nevertheless, the percentage of ethyl ester yield is reduced when the lipase amount reached beyond $5 \%$. This may be because in the presence of a high amount of enzyme, the active site cannot be exposed to the substrates and many molecules of the enzyme aggregate together. ${ }^{57}$

Therefore, a maximum yield higher than 98\% could be obtained working at low catalyst concentrations and high temperature levels.

\section{Influence of $(T-C)$ interactions}

The linear and non-linear models (Central Composite Design) yield binary influences of the two factors used in the design. The main outcome of the combine effects of temperature and catalyst concentration ( $\mathrm{T}-\mathrm{C})$ is significant, and negatively affects the process of ethyl ester production. This behaviour can be explained by the deactivation of the enzyme due to high temperatures that will have negative effects on its activity. This effect has been seen in other enzymes; Sharma et $a l .{ }^{57}$ studied the effect of temperature on the activity of Enzyme FDS8(L) from Bacillus mycoides and found that an increase in temperature has a significant effect within the enzyme activity. Similarly, Zulfiqar et $a .^{58}$ have also found that the activity of the enzyme under consideration, Lipase-PDA. $\mathrm{TiO}_{2} \mathrm{NPS}$, also suffers from deactivation when the reaction temperature was increased. The activity decreased by a factor of 5 when increasing the temperature from 30 to 50 degrees.

Therefore, the results obtained for the enzyme Eversa show agreement with those published previously.

\section{Analysis of response: ester yields}

The FAEE yield is defined as the weight percentage of ethyl ester with respect to the amount of vegetable oil (jatropha oil) poured into the reactor.

The significance of the statistical model can be visualized by representing the response (ester conversion) as a function of the two important factors (temperature and enzyme concentration). Fig. 2 shows the surface and the contour plot of $\mathrm{EE}$ yields versus temperature and catalyst concentration when single experimental data are used. The contour plot shows that the maximum ester yield ( $\mathrm{YEE}=98.5 \%$ ) is achieved working with a temperature in the range of $35-40{ }^{\circ} \mathrm{C}$ using an enzyme concentration of $4-5 \%$.

Insufficient amount of catalyst and lower temperatures resulted in incomplete conversion of free fatty acids and triglycerides into esters. This could be related to the deactivation of the catalyst as well as to not having sufficient energy to overcome the activation energy of the reaction. However, higher reaction temperatures can also lead to problems since there could be evaporation of the alcohol and, therefore, a reduction in the molar ratio, which also affects the final yield.
Furthermore, the presence of water due to the esterification reaction of fatty acids could lead to deactivation of the enzyme. $^{59-61}$

However, from a technical point of view, the highest possible yield for the ethyl esters should be targeted; consequently, a catalyst concentration of $4.2 \%$, an operation temperature of $36{ }^{\circ} \mathrm{C}$ and an alcohol/oil molar ratio of $6: 1$ should be selected. According to these conditions, conversion rates higher than 98.5\% for EE could be obtained.

Tacias-Pascacio et al. ${ }^{62}$ obtained an experimental yield of over $90 \%$ when using Thermomyces lanuginosus immobilized over octadecyl methacylate when using methanol under similar operational conditions to those used in the work (molar ratio of 9:1 and 7\% of catalysts).

Furthermore, the results obtained in this work are also in agreement with those presented by Guldhe et al., ${ }^{63}$ where different enzymes were compared, and their yield reported. They reported yields of $92 \%, 87 \%$, and 95\%, for enzymes Candida antarctica, Candida rugosa, and Thermomyces lanuginosus respectively, under similar conditions.

Fig. 5 shows the residual distribution over the experimental data for the response studied EE yield. The quality of the fit is good since there is no trend that the residual distribution follows. All the residuals are less than $4 \%$ for EE yield, which indicate that the models adequately represent the ethyl ester yield over the experimental range studied.

\section{Quality control of ethyl esters}

After purification, the leftover could be used as a substitute of the diesel fuel, since it matches the European Biodiesel Standard EN 14214 in all aspects tested except for the oxidation time. The important quality parameters of biodiesel (viscosity, acid value, ester content, cloud point, pour point, cold filter plugging point and oxidative stability for optimum reaction conditions) are shown in Table 4 . The experimentally determined values are in great agreement with those of the EN 14214. The acid value was $0.22 \mathrm{mg} \mathrm{KOH} \mathrm{g}^{-1}$, substantially under the maximum of $0.5 \mathrm{mg} \mathrm{KOH} \mathrm{g}{ }^{-1}$ set in the normative and the kinematic viscosity of EE was $4.71 \mathrm{~mm}^{2} \mathrm{~s}^{-1}$ at $40{ }^{\circ} \mathrm{C}$, which is within the specified range.

The product is appropriate to be directly used as a biodiesel in cold and hot climate zones, like those where jatropha plant

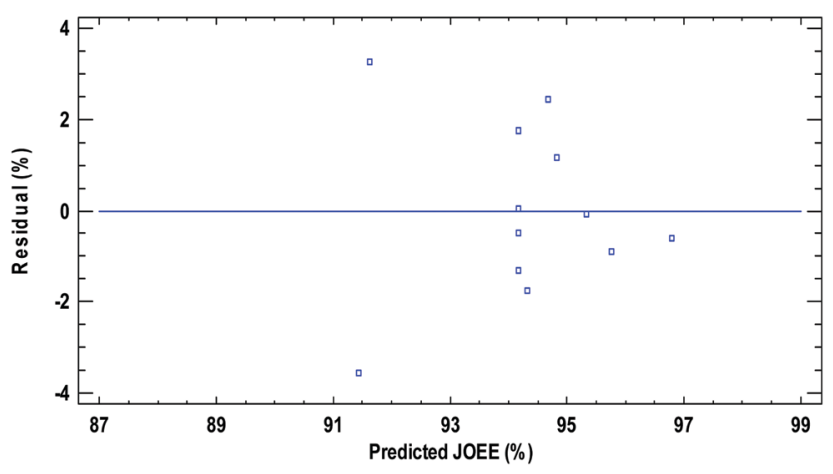

Fig. 5 Residual plots of ethyl ester yield for the second-order model. 
Table 4 Quality control of ethyl ester compared to EN 14214

\begin{tabular}{|c|c|c|}
\hline Properties & Biodiesel & EU Standard EN 14214 \\
\hline Viscosity at $40^{\circ} \mathrm{C}$ & 4.71 & $\operatorname{Max} 5.00 \mathrm{~mm}^{2} \mathrm{~s}^{-1}$ \\
\hline Acid value $\left(\mathrm{mg} \mathrm{KOH} \mathrm{g}^{-1}\right)$ & 0.22 & Max $0.50 \mathrm{mg} \mathrm{KOH} \mathrm{g}^{-1}$ \\
\hline Water content & 200 & Max $500 \mathrm{mg} \mathrm{kg}^{-1}$ \\
\hline Ester contents (wt\%) & 98.5 & Min $96.5 \%\left(\mathrm{~m} \mathrm{~m}^{-1}\right)$ \\
\hline Monoglyceride content (wt\%) & 0.15 & Max $0.80 \%\left(\mathrm{~m} \mathrm{~m}^{-1}\right)$ \\
\hline Diglyceride content (wt \%) & 0.10 & Max $0.20 \%\left(\mathrm{~m} \mathrm{~m}^{-1}\right)$ \\
\hline Triglyceride content (wt\%) & 0.10 & Max $0.20 \%\left(\mathrm{~m} \mathrm{~m}^{-1}\right)$ \\
\hline Free glycerol (wt\%) & 0.01 & Max $0.02 \%\left(\mathrm{~m} \mathrm{~m}^{-1}\right)$ \\
\hline Total glycerol (wt\%) & 0.12 & Max $0.25 \%\left(\mathrm{~m} \mathrm{~m}^{-1}\right)$ \\
\hline Cloud point $\left({ }^{\circ} \mathrm{C}\right)$ & -4.00 & $a$ \\
\hline Pour point $\left({ }^{\circ} \mathrm{C}\right)$ & -6.00 & $a$ \\
\hline Oxidative stability (h) & 2.44 & Min $8 \mathrm{~h}$ \\
\hline
\end{tabular}

${ }^{a}$ Not specified. EN 14214 uses time- and location-dependent values for the cold filter plugging point (CFPP) instead.

is grown. The use of ethanol as the alcohol improved the cold flow properties of the EE in terms of the cloud point (CP), pour point (PP) and cold filter plugging point (CFPP).

The low temperature operability of the biodiesel is normally determined by three common parameters, namely, cloud point (CP), pour point (PP) and cold filter plugging point (CFPP). The CFPP is generally considered to be a more reliable indicator for low-temperature operability than $\mathrm{CP}$ or PP, since the fuel will contain solids of sufficient size to render the engine inoperable due to fuel filter plugging once the CFPP is reached. ${ }^{64}$ The CP, PP and CFPP of the biodiesel samples are shown in Fig. 6. The biodiesel samples displayed a cloud point (CP) of $-4{ }^{\circ} \mathrm{C}$, a pour point (PP) of $-6{ }^{\circ} \mathrm{C}$ and a cold filter plugging point (CFPP) of $-6{ }^{\circ} \mathrm{C}$. Producing biodiesel fuels from high free fatty acid jatropha oil using ethanol as the alcohol improved the cold flow properties in terms of CP, PP and CFPP compared to those obtained using methanol as the alcohol in the transesterification process.

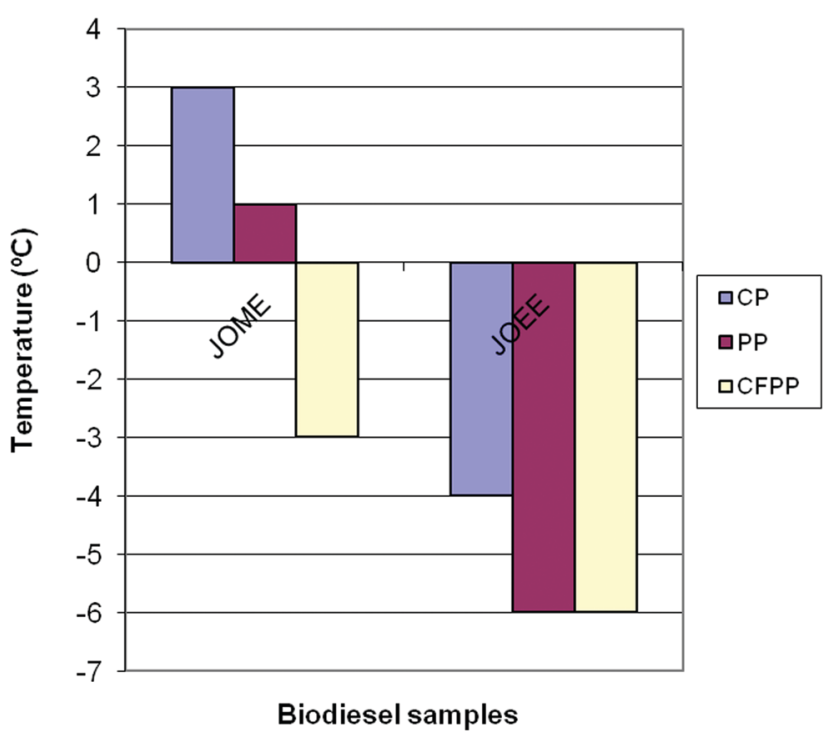

Fig. 6 CP, PP and CFPP of biodiesel sample jatropha oil methyl ester (JOME) and jatropha oil ethyl ester (JOEE).
The oxidative stability of ethyl esters was determined by the Rancimat method EN 14214, and the average of two tests was close to $2.5 \mathrm{~h}$. The oxidative stability increases when the induction periods (IP) do. The EE samples are less stable against free radical attack (IP values of $2.5 \mathrm{~h}$ ). The biodiesel produced from jatropha oil using ethanol as the alcohol displayed poor oxidative stability in terms of the Rancimat test compared to those obtained using methanol in the transesterification process. The biodiesel sample does not meet the oxidative stability requirements in the EN 14214 standard. The IP of the samples was the function of their fatty acid profile. The use of commercial synthetic or natural antioxidants could improve the oxidation stability of the biodiesel fuel tested. ${ }^{65}$

In accordance with the EN 14214, the monoglyceride (MG) content should be lower than $0.8 \mathrm{wt} \%$, and the content of diglycerides (DG) and triglycerides (TG) lower than $0.2 \mathrm{wt} \%$, each. In addition, the ester content should be greater than or equal to $96.5 \mathrm{wt} \%$. For the EE fraction, the ester content was 98.5\% and individual glyceride (MG, DG and TG) concentrations were also matching the specifications, which imply that the esterification/transesterification reactions were complete.

When carrying out the ester purification, this technique produced some loss of enzymes, and the overall loss in activity was around $40 \%$ using the enzyme less than 3 times. Additional research should be carried out to look for techniques to recover enzymes effectively and efficiently to be reused many times.

\section{Conclusions}

In the present work, an effort has been made to valorise high free fatty acid jatropha oil as a cheap raw material for low-cost biodiesel production. The effects of temperature reaction and enzyme concentration on ethyl ester synthesis using Novozymes Eversa Transform 2.0 as a biocatalyst have been studied and optimized. The Novozymes Eversa enzyme showed enhanced stability to denaturation by ethanol under the optimum conditions. The maximum yield of ethyl esters (98.5\%) can be obtained when running the process at their optimal molar ratio of $6: 1$, with a steering of $350 \mathrm{rpm}$, at atmospheric pressure with a reaction temperature of $36{ }^{\circ} \mathrm{C}$ and a catalyst amount of $4.2 \mathrm{wt} \%$. The biodiesel produced from high FFA jatropha oil by one-step enzymatic catalysis fulfils almost all the specification of European Union Standards (EN 14214), except for the oxidation time. In addition, it was found that the biodiesel produced from this high fatty acid source presented an improvement in their properties, making it a better fuel for cold weather. In addition, Novozymes Eversa Transform 2.0 was easy to recover and there is no contamination of the final product, saving time and cost in the purification step. Since Novozymes Eversa Transform 2.0 is cheaper than Novozymes 435 , it would be advantageous in future large-scale studies and industrial applications, making the process environmentally acceptable and economically competitive.

This enzymatic route could be a promising low-cost biodiesel production strategy using a cheap raw material. Further 
research is needed to make the process more economic and eco-friendlier.

\section{Nomenclature}

$\begin{array}{ll}\text { FAEE } & \text { Fatty acid ethyl esters } \\ C & \text { Catalyst concentration } \\ T & \text { Reaction temperature, }{ }^{\circ} \mathrm{C} \\ T_{\mathrm{C}} & \text { Temperature-catalyst concentration interaction } \\ X_{\mathrm{i}} & \text { Level of factor } i \\ Y & \text { Ester conversion, } \% \\ n & \text { Number of factors in a factorial design } \\ r & \text { Correlation coefficient } \\ t & \text { Student's } t \text { value } \\ s & \text { Standard deviation } \\ \alpha & \text { Distance from the origin to star point in a central } \\ & \text { composite design } \\ Y & \text { Mean response for the factorial design } \\ Y_{\mathrm{c}} & \text { Mean centre point response } \\ a_{0} & \text { Intercept } \\ a_{\mathrm{k}} & \text { First-order model coefficient } \\ a_{\mathrm{kk}} & \text { Quadratic coefficient for the } i \text { th variable } \\ a_{\mathrm{kj}} & \text { Interaction coefficients for the interaction of variables } \\ & \text { k and j } \\ X_{\mathrm{k}} & \text { Independent variables }\end{array}$

\section{Author contributions}

Abderrahim Bouaid: Software, resources, methodology, supervision, formal analysis, conceptualization, writing orignal draft. Hassan Acherki: resources, methodology, data curation, supervision. Marcos Herguedas Bonilla: investigation, data curatin. Jorge Mario Marchetti: funding, writing - review and editing.

\section{Conflicts of interest}

There are no conflicts to declare.

\section{Acknowledgements}

Financial support from: Research Santander-Complutense University Project (PR41/17-20953)is gratefully acknowledged. Financial Support from NMBU is gratefully appreciate it.

\section{Notes and references}

1 A. Rezayan and M. J. P. S. Taghizadeh, Process Saf. Environ. Prot., 2018, 117, 711.

2 M. Ali, J. Gimbun, K. L. Lau, C. K. Cheng, D. Vo, S. S. Lam and R. Yunus, Environ. Res., 2020, 185, 109452.

3 M. Athar and S. Zaidi, J. Environ. Chem. Eng., 2020, 24, 104523.

4 N. S. Talha and S. Sulaiman, J. Eng. Appl. Sci., 2016, 11, 439.

5 M. Serrano, A. Bouaid, M. Martínez and J. Aracil, Fuel, 2013, 113, 50 .
6 P. T. Anastas and J. C. Warner. Green Chemistry: Theory and Practice, Oxford University Press, New York, 1998.

7 P. Adewale, L. V. Nilmini and L. Christopher, Energy Convers. Manage., 2017, 154, 81.

8 European Commission, Agricultural Medium-Term Agricultural Outlook 2016-2026.

9 Transport \& Environment (T\&E) analysis of Globiom results, 2016.

10 S. N. Gebremariam and J. M. Marchetti, Energy Convers. Manage., 2018, 168, 74.

11 J. Tomei and R. Helliwell, Land Use Policy, 2016, 56, 320.

12 L. P. Christopher, H. Kumar and V. P. Zambare, Appl. Energy, 2014, 119, 497.

13 A. E. Atabani, A. S. Silitonga, H. C. Ong, T. M. I. Mahlia, H. H. Masjuki, I. A. Badruddin and H. Fayaz, Renewable Susainble Energy Rev., 2013, 18, 211.

14 A. Bouaid, R. Vázquez, M. Martinez and J. Aracil, Fuel, 2016, 174, 54.

15 P. Adewale, M. J. Dumont and M. Ngadi, Renewable Sustainable Energy Rev., 2015, 45, 574.

16 A. Bouaid, N. El boulifi, K. Hahati, M. Martinez and J. Aracil, Chem. Eng. J., 2014, 238, 234.

17 A. Bouaid, N. El boulifi, M. Martinez and J. Aracil, Int. J. Low Carbon Technol., 2012, 7(4), 331.

18 Y. Zhang, M. A. Dube, D. D. McLean and M. Kates, Bioresour. Technol., 2003, 90, 229.

19 A. V. Tomasevic and S. S. Siler-Marinkovic, Fuel, 2003, 81, 1. 20 S. Fernando, P. Karra, R. Hernandez and S. Kumar, Energy, 2007, 32, 844.

21 Y. C. Sharma, B. Singh and S. N. Upadhyay, Fuel, 2008, 87, 2355.

22 J. Pullen and K. Saeed, Renewable Sustainable Energy Rev., 2012, 16, 5924.

23 M. J. Rushang and J. P. Michael, Fuel, 2007, 86, 143-151.

24 J. Pullen and K. Saeed, Renewable Sustainable Energy Rev., 2012, 16, 5924.

25 M. J. Bosswell, Proc. International conference of Renewable Energy Technology for rural Development, Kathmandu, Nepal, 2003, vol. 12-14.

26 A. Bouaid, M. Martinez and J. Aracil, Bioresour. Technol., 2009, 100(7), 2234.

27 L. Tao, X. He, C. D. Eric, M. Tan, M. Zhang and A. Aden, Biofuels, Bioproducts Biorefinery, 2014, 8, 342.

28 A. Zarei, N. A. S. Amin, A. T. Kiakalaieh and N. A. M. Zain, Journal of the Taiwan Institute of Chemical Engineering, 2014, 45, 444.

29 S. Prasad and I. Roy, Biotechnoly, 2017, 12, 33.

30 R. A. Sheldon and J. M. Woodley, Chem. Rev., 2018, 118, 801.

31 H. Sun, H. Zhang, E. L. Ang and H. Zhao, Bioorg. Med. Chem., 2018, 26, 1275.

32 R. N. Patel, Bioorg. Med. Chem., 2018, 26, 1252.

33 A. Madhavan, R. Sindhu, P. Binod, R. K. Sukumaran and A. Pandey, Bioresour. Technol., 2017, 245, 1304.

34 R. Singh, M. Tiwari, R. Singh and J. K. Lee, Int. J. Mol. Sci., 2013, 14, 1232.

35 P. Grunwald. Industrial Biocatalysis, CRC Press, New York, 2015, pp. 1-32. 
36 S. Santos, J. Puna and J. Gomes., Energies, 2020, 13(11), 3013.

37 R. Fernandez-Lafuente, J. Mol. Catal. B: Enzym., 2010, 62, 197.

38 V. G. Tacias-Pascacio, B. Torrestiana-Sanchez, L. Dal Magro, J. J. Virgen Ortíz, F. J. Suarez-Ruíz, R. C. Rodrigues and R. Fernandez-Lafuente, Renewable Energy, 2019, 135, 1.

39 V. G. Tacias-Pascacio, J. J. Virgen-Ortíz, M. Jimenez-Perez, M. Yates, B. Torrestiana-Sanchez, A. Rosales-Quintero and R. Fernandez-Lafuente, Fuel, 2017, 200, 1.

40 GCC. Novozymes launches commercial enzyme technology to convert waste oils into biodiesel. Green car congress. 2014. https://www.greencarcongress.com/2014/12/20141202novozymes.html.

41 P. M. Nielsen, A. Rancke-Madsen, H. C. Holm and R. Burton, J. Am. Oil Chem. Soc., 2016, 93, 905.

42 M. Coppini, J. D. Magro, R. Martello, A. Valerio, M. C. Zenevicz, D. De Oliveira and J. V. Oliveira, Brazilian J. Chem. Eng., 2019, 36, 923.

43 J. H. C. Wancura, M. V. Tres, S. L. Jahn and J. V. Oliveira, Biotechnol. Appl. Biochem., 2020, 67, 648.

44 G. M. Mibielli, A. P. Fagundes, J. P. Bender and J. Vladimir Oliveira, Bioresource Technology Reports, 2019, 5, 150.

45 T. Andrade, M. Martín, M. Errico and K. Christensen, Chem. Eng. Res. Design, 2019, 141, 1.

46 G. Box and J. Hunter, Response surface methods, Statistics for experiments, part IV: building models and using them, New York, John Wiley \& Sons, ch. 5, 1978.

47 B. Vlada, A. Veljković, S. Olivera and S. Stamenković, Chin. J. Chem. Eng., 2019, 27, 1690.

48 A. Bouaid, M. Martinez and J. Aracil, Chem. Eng. J., 2007, 134, 93.

49 A. Bouaid, J. Aparecio, M. Martinez and J. Aracil, Enzyme Microb. Technol., 2007, 41, 533.
50 T. A. Andrade, M. Errico and K. V. Christensen, Comput.-Aided Chem. Eng., 2017, 40, 2863.

51 M. Balat and H. Balat, Appl. Energy, 2010, 87, 1815.

52 G. T. Jeong and D. H. Park, Appl. Biochem. Biotechnol., 2008, 1, 131.

53 A. Bouaid, Y. Diaz, M. Martinez and J. Aracil, Catal. Today, 2005, 106, 193.

54 J. Box and W. Wilson, J. R. Stat. Soc., 1951, 1, 1.

55 H. V. Lee, R. Yunus, J. C. Juan and Y. H. Taufiq-Yap, Fuel Process. Technol., 2011, 92, 2420.

56 Y. Jiang, X. Liu, Y. Chen, L. Zhou, Y. He, L. Ma and J. Gao, Bioresour. Technol., 2014, 153, 278.

57 D. Sharma, S. Uniyal and L. Tewari, Process Biochem., 2021, 111, 43.

58 A. Zulfiqar, M. W. Mumtaz, H. Mukthar, J. Najeeb, A. Irfan, S. Akram, T. Touqeer and G. Nabi, Renewable Energy, 2021, 169, 1026.

59 J. Calero, C. Verdugo, D. Luna, E. D. Sancho, C. Luna, A. Posadillo, F. M. Bautista and A. A. Romero, New Biotechnol., 2014, 31, 596.

60 G. Trubiano, D. Borio and A. Errazu, Enzyme Microb. Technol., 2007, 40, 716.

61 J. M. Encinar, J. F. Gonzalez, N. Snaches and S. N. Delvgado, Bioprocess Biosyst. Eng., 2019, 42, 157.

62 V. G. Tacias-Pascacio, B. Torrestiana-Sanchez, L. D. Magro, J. J. Virgen-Ortiz, F. J. Suarez-Ruiz, R. C. Rodrigues and R. F. Lafuente, Renewable Energy, 2019, 135, 1.

63 A. Guldhe, B. Singh, T. Mutanda, K. Permaul and F. Bux, Renewable Sustainable Energy Rev., 2015, 41, 1447.

64 G. Knothe, S. Cermak and R. Evangelista, Energy Fuels, 2009, 23, 1743.

65 U. Rashid, F. Anwar, R. Bryan, B. Moser and G. Knothe, Bioresour. Technol., 2008, 99(17), 8175. 